\title{
Definitions of primary graft dysfunction after lung transplantation: Differences between bilateral and single lung transplantation
}

Takahiro Oto, MD, Anne P. Griffiths, FRCNA, Bronwyn J. Levvey, RN, David V. Pilcher, MRCP, Trevor J. Williams, FRACP, and Gregory I. Snell, FRACP

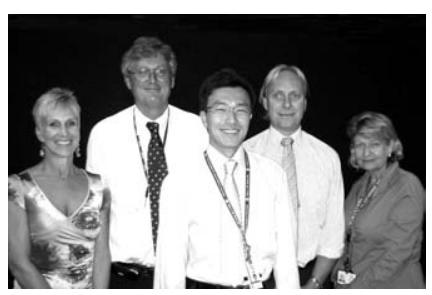

Bronwyn J. Levvey, RN, Trevor J. Williams, FRACP, Takahiro Oto, MD, Gregory I. Snell, FRACP, and Anne P. Griffiths, FRCNA (left to right)

$\mathcal{B}$ Additional material is available online.
From the Department of Allergy, Immunology, and Respiratory Medicine, Heart and Lung Transplant Unit, The Alfred Hospital, Monash University, Melbourne, Australia.

Supported by the Margaret Pratt Foundation and the Alfred Foundation.

Received for publication Dec 24, 2005; revisions received March 6, 2006; accepted for publication March 21, 2006.

Address for reprints: Gregory I. Snell, FRACP, Department of Allergy, Immunology, and Respiratory Medicine, The Alfred Hospital, Commercial Rd, Melbourne, Victoria 3004, Australia (E-mail: g.snell@ alfred.org.au).

J Thorac Cardiovasc Surg 2006;132:140-7

$0022-5223 / \$ 32.00$

Copyright $\odot 2006$ by The American Association for Thoracic Surgery

doi:10.1016/j.jtcvs.2006.03.029
Objective: The primary graft dysfunction definition has been applied to both bilateral lung transplantation and single lung transplantation. However, the differences between bilateral and single lung transplantation in terms of primary graft dysfunction remain unknown. This study aims to investigate the features and utility of the new primary graft dysfunction grading system by comparing early outcomes from bilateral and single lung transplantation.

Methods: The primary graft dysfunction grade of 228 consecutive lung transplants (149 bilateral and 79 single lung transplants) at multiple postoperative time points was analyzed. Subgroup analysis with chronic obstructive pulmonary disease was performed to further validate the difference between bilateral lung transplantation and single lung transplantation.

Results: The percentage of grade 3 primary graft dysfunction in bilateral and single lung transplants was $32 \%$ and $37 \%$ at 0 hours (T0), $9 \%$ and $33 \%$ at 12 hours (T12), $7 \%$ and $26 \%$ at 24 hours (T24), and $9 \%$ and $18 \%$ at 72 hours (T72), respectively. The prevalence of the grade 3 primary graft dysfunction (T24) was significantly different between those undergoing bilateral lung transplantation and those undergoing single lung transplantation $(P=.02)$. The primary graft dysfunction grade (T0) significantly correlated with the duration of intubation in both bilateral $(r=$ $0.35, P<.0001)$ and single $(r=0.42, P=.001)$ lung transplantation and length of intensive care unit stay in both bilateral $(r=0.31, P=.0002)$ and single $(r=0.33$, $P=.006)$ lung transplantation. These differences were validated by the subgroup analysis.

Conclusions: The prevalence of primary graft dysfunction grade is different between bilateral and single lung transplantation and varies with time. Although the primary graft dysfunction grade correlated with the early posttransplantation outcomes, for the purposes of description and further studies, primary graft dysfunction in bilateral and single lung transplantation should be considered separately.

$\mathrm{P}$ rimary graft dysfunction (PGD), a severe form of acute lung injury developing in the immediate postoperative period, is responsible for significant morbidity and mortality after lung transplantation. ${ }^{1-6}$ It is apparent that a standardized definition and a grading system will ultimately help in the diagnosis, treatment, and prevention of PGD. ${ }^{7}$ The International Society for Heart and Lung Transplantation (ISHLT) Working Group on Primary Graft Dysfunction has recently reported a standardized consensus defining criteria of PGD, which is based on the recipient $\mathrm{PaO}_{2} /$ fraction of inspired oxygen $\left(\mathrm{FiO}_{2}\right)$ value and results of chest radiography, and this has been applied to both bilateral lung transplantations (BLTs) and single lung transplantations (SLTs). ${ }^{7-12}$ 


$$
\begin{aligned}
& \text { Abbreviations and Acronyms } \\
& \begin{aligned}
\mathrm{BLT} & =\text { bilateral lung transplantation } \\
\mathrm{CI} & =\text { confidence interval } \\
\mathrm{COPD} & =\text { chronic obstructive pulmonary disease } \\
\mathrm{FIO}_{2} & =\text { fraction of inspired oxygen } \\
\mathrm{ICU} & =\text { intensive care unit } \\
\mathrm{ILD} & =\text { interstitial lung disease } \\
\mathrm{ISHLT} & =\text { International Society for Heart and Lung } \\
& \text { Transplantation } \\
\mathrm{PEEP} & =\text { positive end-expiratory pressure } \\
\mathrm{PGD} & =\text { primary graft dysfunction } \\
\mathrm{SLT} & =\text { single lung transplantation }
\end{aligned}
\end{aligned}
$$

Several studies have attempted to show the effect of transplant type on posttransplantation outcomes, including PGD. The results, however, are inconclusive because these early studies used different PGD definitions and different outcome variables and included different recipient underlying diseases. ${ }^{1,2,4,6,13,14}$ In reality, $\mathrm{PaO}_{2} / \mathrm{FIO}_{2}$ early after transplantation is actually a changing variable, ${ }^{3}$ and the type of transplantation might possibly significantly influence $\mathrm{PaO}_{2} /$ $\mathrm{FIO}_{2}$ and consequent PGD grading.

Therefore we hypothesize that the components of PGD grading might differ between BLT and SLT at multiple posttransplantation time points. The aim of this study is to investigate the features and utility of the new PGD grading system by comparing early outcomes from BLTs and SLTs.

\section{Patients and Methods}

From January 2000 through October 2005, a total of 228 consecutive lung transplantations performed at The Alfred Hospital, including 149 BLTs and 79 SLTs, were included in this retrospective study.

\section{Study Group}

All patients were divided into those who received BLTs (BLTtotal group) and those who received SLTs (SLT-total group). To further validate the difference between the types of transplantations, patients with chronic obstructive pulmonary disease (COPD) were also analyzed separately. The diagnosis of COPD here was defined to include smoking-related emphysema (78\%), $\alpha 1$-antitrypsin deficiency $(10 \%)$, obliterative bronchiolitis $(10 \%)$, and bronchial asthma (2\%). The patients with COPD were divided into 2 groups according to the type of transplantation (BLT-COPD and SLT-COPD groups).

\section{PGD Grading}

Details of PGD grading severity have been described elsewhere. ${ }^{8}$ Briefly, the classification scheme is based on 2 clinical parameters, including the chest radiograph and $\mathrm{PaO}_{2} / \mathrm{FIO}_{2}$ ratio. $\mathrm{A} \mathrm{PaO}_{2} / \mathrm{FIO}_{2}$ ratio of greater than 300 without radiographic infiltrates is considered grade 0 , a $\mathrm{PaO}_{2} / \mathrm{FIO}_{2}$ ratio of greater than 300 with radiographic infiltrates is considered grade 1 , a $\mathrm{PaO}_{2} / \mathrm{FIO}_{2}$ ratio of between 200 and 300 with radiographic infiltrates is considered grade 2, and $\mathrm{PaO}_{2} / \mathrm{FIO}_{2}$ ratio of less than 200 with radiographic infiltrates is considered grade 3 . There are other specific inclusionexclusion criteria. For example, any patient using a nasal cannula for oxygen or with an $\mathrm{FIO}_{2}$ of less than 0.3 is graded as 0 or 1 on the basis of chest radiography; absence of infiltrates on chest radiography is sufficient for grade 0 , even if the $\mathrm{PaO}_{2} / \mathrm{FIO}_{2}$ ratio is less than 300; any patient mechanically ventilated with $\mathrm{FIO}_{2}$ of greater than 0.5 on nitric oxide beyond 48 hours after transplantation is graded as grade 3; and any patient receiving extracorporeal membrane oxygenation is automatically considered grade $3{ }^{8}$

\section{Transplantation Protocol}

Donor assessment and management, donor-recipient matching, surgical technique, and postoperative management proceeded according to our standard protocol, which has been described elsewhere. ${ }^{15-17}$ Although lung donor selection criteria are based on standard criteria, extended donors are commonly considered and used at our institution.

Preoperative immunologic evaluation was routinely performed. The presence of preformed antibodies to human leukocyte antigen was assessed with a panel-reactive antibody assay, and a prospective donor-recipient T-cell and B-cell cross-match was performed in the vast majority of cases.

\section{Lung Procurement and Preservation}

Lung procurement and preservation followed standard procedures. ${ }^{18,19}$ This includes an intravenous infusion of prostacyclin (Flolan; Wellcome, Sydney, Australia) at 40 to $80 \mathrm{ng} \cdot \mathrm{kg}^{-1}$. $\min ^{-1}$ for approximately 10 minutes before crossclamping, followed by single antegrade flush with cold modified Euro-Collins solution (60 mL/kg). From September 2004, Perfadex (Vitrolife, Göteborg, Sweden) replaced Euro-Collins solution at our institution. Before implantation, an exploratory retrograde initial flush was performed to detect any unexpected pulmonary emboli in the donor lung graft. ${ }^{10}$

\section{Transplantation Procedure}

Cardiopulmonary bypass was not routinely performed in our institution for BLT or SLT. Cardiopulmonary bypass was considered when intolerance of single lung ventilation caused by hemodynamic instability was seen. ${ }^{20}$ Before completion of implantation, retrograde, followed by antegrade, reperfusion and deairing was performed through an untied pulmonary arterial anastomotic suture line. A specific pressure- and flow-controlled technique, including leukocyte filtration, was not used.

\section{Postoperative Management}

Postoperative management in the intensive care unit (ICU) was performed to ensure satisfactory end-organ perfusion while maintaining a relatively low filling pressure (cardiac index, $>2.4$; pulmonary capillary wedge pressure, $<10 \mathrm{~mm} \mathrm{Hg}$; and central venous pressure, $<7 \mathrm{~mm} \mathrm{Hg}$ ). ${ }^{21}$ Patients with PGD received a standardized evaluation and therapy with increasing complexity, depending on the degree of ventilatory and hemodynamic compromise. A retrospective cross-match was performed to exclude humoral rejection. Transesophageal echocardiography was performed to exclude lung torsion, pulmonary vascular obstruction, or both. Therapy included pressure-controlled mechanical ventilation with limitation of positive end-expiratory pressure, negative fluid 
balance with furosemide or continuous venovenous hemofiltration, inhaled nitric oxide at a dose of 5 to $20 \mathrm{ppm}$, and elevation of the upper body or lateral positioning, if appropriate. For persistent PGD beyond these approaches, extracorporeal membrane oxygenation was considered. ${ }^{22}$

\section{Immunosuppression}

Immunosuppression was based on triple therapy with cyclosporine (INN: ciclosporin; trough levels of 300-450 $\mu \mathrm{g} / \mathrm{L}$ ), azathioprine

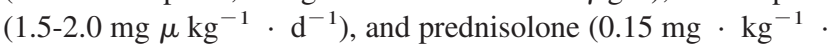
$\mathrm{d}^{-1}$ ), and prophylaxis for Pneumocystis carinii and cytomegalovirus infection was achieved with low-dose oral trimethaprimsulfamethoxazole and intravenous ganciclovir and oral valganciclovir, respectively. ${ }^{16}$

\section{Data Collection}

All of the data were collected from an institutional transplantation database and from a review of ICU records. The $\mathrm{PaO}_{2} / \mathrm{FIO}_{2}$ ratio was collected every 6 hours in the first 72 hours after final reperfusion. When blood gas analysis data at a specific time point were not available, data closest to the time point were substituted. The donor $\mathrm{PaO}_{2} / \mathrm{FIO}_{2}$ ratio was the arterial blood gas result on $\mathrm{FIO}_{2}$ of 1.0 recorded at the time of organ procurement. The graft ischemic time of a BLT was defined as the ischemic time for the second transplanted lung in this study. The presence or absence of radiographic infiltrates consistent with pulmonary edema every 24 hours after transplantation was assessed by blinded reviewers. In the BLT group a unilateral infiltrate was defined as an abnormal radiograph.

\section{Assessment of Outcome of PGD}

Duration of intubation, length of ICU stay, and 30-day mortality were used as outcome indicators of PGD.

\section{Statistical Analysis}

Continuous data were initially assessed for normality and expressed as means \pm standard error. Categoric data were expressed as counts and proportions. Comparison between groups was performed with the $\chi^{2}$ or Fisher exact tests for categoric variables, with the Student $t$ test for parametric continuous variables, or with the Mann-Whitney $U$ test for nonparametric continuous variables, if appropriate. Repeated-measures variables, including $\mathrm{PaO}_{2} / \mathrm{FIO}_{2}$ ratio, were analyzed with 2-way repeated-measures analysis of variance, and multiple comparisons between PGD grades were analyzed with factorial analysis of variance, followed by the posthoc test. The duration of intubation and length of ICU stay were estimated by using the Kaplan-Meier method, and the curves were analyzed by using the log-rank test. Correlation analysis between PGD grade and the duration of intubation and length of ICU stay were performed by using Pearson correlation analysis. Univariate analysis for 30-day mortality was conducted with logistic regression. Analysis was performed with the Statview 5.0 software package (SAS Institute Inc, Cary, NC).

\section{Results}

Donor and Recipient Demographics

Demographics of the donors and recipients are shown in Table E1. The ages of the recipients in both the BLT-total and BLT-COPD groups were significantly younger than those in the SLT-total and SLT-COPD groups $(P<.0001$ and $P=.0008$, respectively). All of the patients with cystic fibrosis and pulmonary hypertension underwent BLT.

\section{Time from First and Second Lung Reperfusion to Admission to the ICU}

In the BLT-total group the times from first and second lung reperfusion to admission to the ICU were $227 \pm 6$ and 114 \pm 6 minutes, respectively. The difference between the first and the second lung reperfusion time was $108 \pm 6$ minutes. In the SLT-total group the time from reperfusion to admission to the ICU was $114 \pm 6$ minutes, and this was similar to that from the second lung reperfusion to admission to the ICU in the BLT-total group. Only 1 patient exceeded 6 hours from final reperfusion to admission to the ICU.

\section{Posttransplantation Oxygenation}

The $\mathrm{PaO}_{2} / \mathrm{FIO}_{2}$ ratio in the first 72 hours after transplantation is shown in Figure 1. The $\mathrm{PaO}_{2} / \mathrm{FIO}_{2}$ ratio in the BLT-total group was significantly greater than that in the SLT-total group throughout the first 72 hours $(P<.0001)$. The $\mathrm{PaO}_{2} /$ $\mathrm{FIO}_{2}$ ratio in the BLT-COPD subgroup was also significantly greater than that in the SLT-COPD subgroup $(P=.002)$. In the BLT groups the $\mathrm{PaO}_{2} / \mathrm{FIO}_{2}$ ratio increased in the first 12 hours and thereafter remained relatively stable throughout the first 72 hours. In contrast, the $\mathrm{PaO}_{2} / \mathrm{FIO}_{2}$ ratio in the SLT groups decreased in the first 6 hours, increased gradually, and then decreased again after 24 hours. The pattern of the curves between the total and COPD groups seemed to be similar. A similar pattern of the curves was also seen in patients with interstitial lung disease (ILD).

\section{Prevalence of $\mathrm{PaO}_{2} / \mathrm{FIO}_{2}$ ratio stratified by PGD criteria}

In the BLT-total group the percentage of patients with a $\mathrm{PaO}_{2} / \mathrm{FIO}_{2}$ ratio of less than 200 decreased in the first 12 hours, from $40 \%$ at 0 hours to $10 \%$ at 12 hours, and remained relatively stable in the subsequent period. In the SLT-total group the percentage of patients with a $\mathrm{PaO}_{2} / \mathrm{FIO}_{2}$ ratio of less than 200 decreased gradually, from $43 \%$ at 0 hours to $24 \%$ at 72 hours. There was a significant difference in the prevalence of patients with a $\mathrm{PaO}_{2} / \mathrm{FIO}_{2}$ ratio of less than 200 at 24 hours $(P=.04)$. Similar trends of prevalence of various $\mathrm{PaO}_{2} / \mathrm{FIO}_{2}$ ratios versus time were seen in the COPD subgroups $(P=.03$, Figure 2$)$.

\section{Chest Radiography}

The relative proportion of patients having an infiltrate on chest radiography at $0,24,48$, and 72 hours was $58 \%, 69 \%$, $67 \%$, and $66 \%$ in the BLT-total group and $65 \%, 79 \%, 77 \%$, and $76 \%$ in the SLT-total group, respectively. In the COPD subgroups the proportions were $49 \%, 61 \%, 59 \%$, and $58 \%$ 

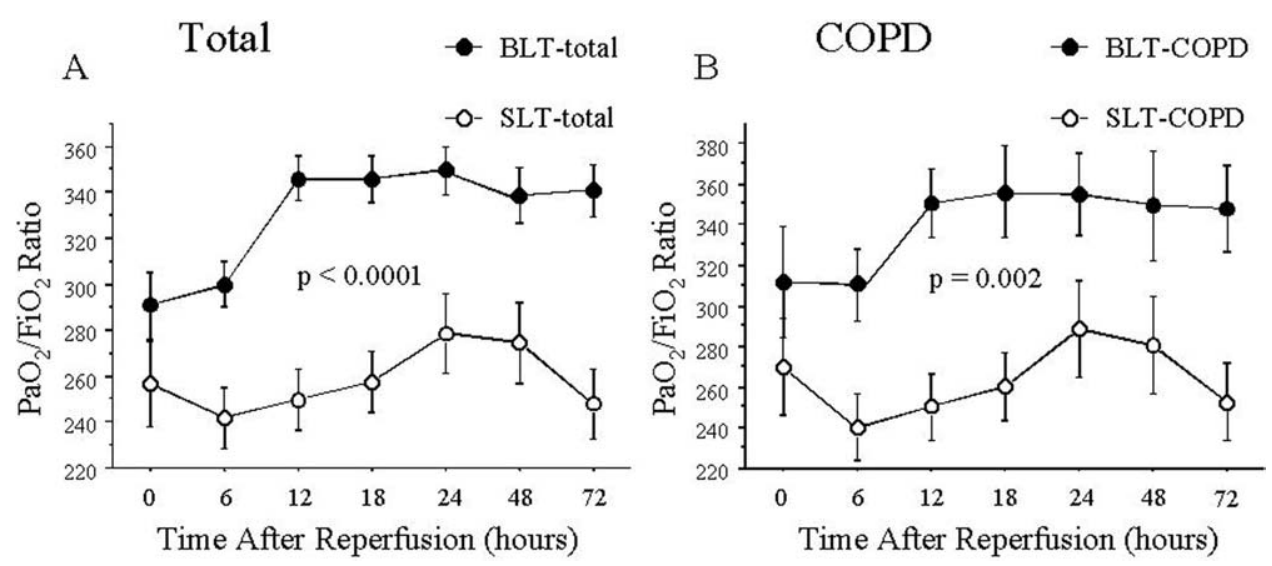

Figure 1. $\mathrm{PaO}_{2}$ /fraction of inspired oxygen $\left(\mathrm{FiO}_{2}\right)$ ratio in the first 72 hours after transplantation. A, Total lung transplant recipients. B, Subgroup analysis for recipients with chronic obstructive pulmonary disease (COPD).

in the BLT-COPD subgroup and $60 \%, 76 \%, 75 \%$, and $70 \%$ in the SLT-COPD subgroup, respectively.

\section{PGD Grading}

In the BLT-total group the percentage of grade 3 PGD decreased in the first 12 hours, from $32 \%$ at 0 hours to $9 \%$ at 12 hours, and remained relatively stable in the subsequent period. In contrast, the percentage of grade 3 PGD in the SLT-total group decreased gradually throughout the first 72 hours, and the actual values were $37 \%$ at 0 hours, $33 \%$ at 12 hours, $26 \%$ at 24 hours, $23 \%$ at 48 hours, and $18 \%$ at 72 hours. A similar trend of prevalence of various PGD grades was seen in the COPD subgroups (Figure 3). Despite the similarity of the percentage of patients remaining intubated versus time in the BLT-COPD and SLT-COPD subgroups, the percentage of patients with PGD grade 3 was higher in the SLT-COPD subgroup throughout the first 72 hours. At 24 hours, the prevalence of grade 3 PGD was significantly different between the 2 subgroups $(P=.03)$.

\section{Duration of Intubation and Length of ICU Stay}

Two $(1.3 \%)$ patients in the BLT-total group and $16(20 \%)$ patients in SLT-total group were extubated in the operating room after transplantation. The duration of intubation in the BLT-total group (median, 19 hours) was significantly longer than that in the SLT-total group (median, 8 hours),

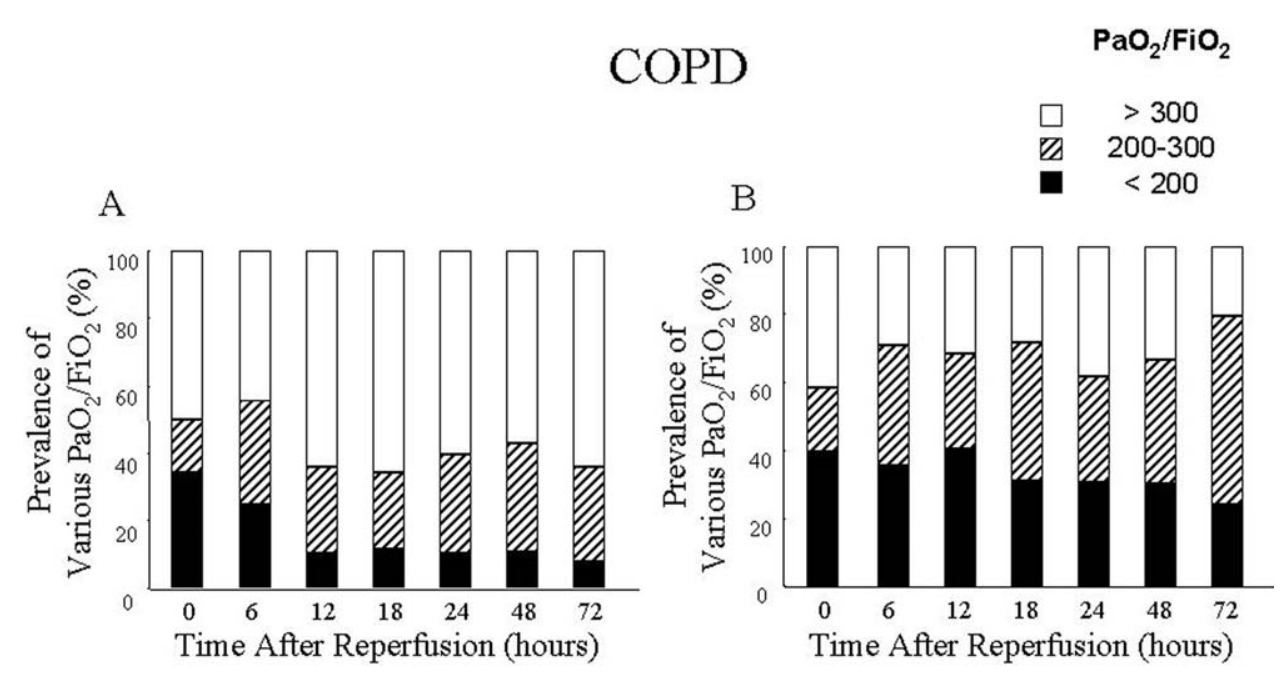

Figure 2. Prevalence of various $\mathrm{Pao}_{2} /$ fraction of inspired oxygen $\left(\mathrm{FlO}_{2}\right)$ ratios in recipients with chronic obstructive pulmonary disease (COPD) stratified by primary graft dysfunction criteria. A, Bilateral lung transplant recipients. B, Single lung transplant recipients. 


\section{COPD PGD grade}

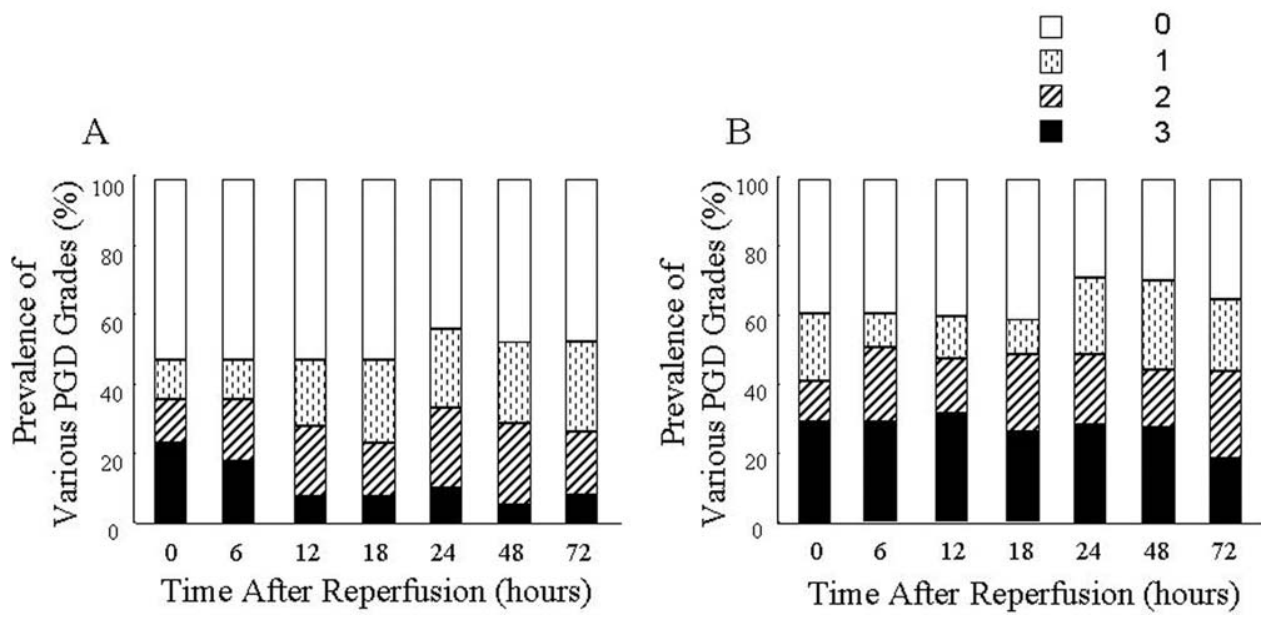

Figure 3. Prevalence of various primary graft dysfunction (PGD) grades in recipients with chronic obstructive pulmonary disease (COPD). A, Bilateral lung transplant recipients. B, Single lung transplant recipients.

and the percentage of patients remaining intubated at 24,48 , and 72 hours was $36 \%, 24 \%$, and $20 \%$ in the BLT-total group and $27 \%, 23 \%$, and $18 \%$ in the SLT-total group, respectively $(P=.03)$. The length of ICU stay in the BLT-total (median, 3 days) and SLT-total (median, 2 days) groups was similar $(P=.36)$. The duration of intubation and length of ICU stay in the COPD subgroups is shown in Figure E1. Although the duration of intubation in the BLTCOPD subgroup (median, 20 hours) tended to be longer than that in the SLT-COPD subgroup (median, 8 hours), there were no significant differences between them $(P=$ .14). The length of ICU stay in the BLT-COPD (median, 3 days) and SLT-COPD (median, 2 days) subgroups was similar $(P=.49)$.
Correlation Between PGD Grade and Early Outcomes There was a significant correlation between the PGD grade at 0 hours and the duration of intubation in the BLT-total $(r$ $=0.35$ [95\% confidence interval [CI], 0.19-0.48], $P<$ $.0001)$ and SLT-total $(r=0.42$ [95\% CI, 0.18-0.62], $P=$ .001) groups. There was also a significant correlation between the PGD grade at 0 hours and the length of ICU stay in the BLT-total ( $r=0.31$ [95\% CI, 0.15-0.45], $P=.0002)$ and SLT-total $(r=0.33$ [95\% CI, 0.10-0.52], $P=.006)$ groups. In the COPD subgroups the correlation between PGD grade and duration of intubation and ICU stay at 0, 24, 48 , and 72 hours are shown in Table 1. In the BLT-COPD subgroup a significant correlation was seen at every time point. In the SLT-COPD subgroup a significant correlation

Table 1. Correlation between primary graft dysfunction grade and duration of intubation/intensive care unit stay

\begin{tabular}{|c|c|c|c|c|c|c|}
\hline \multirow[b]{2}{*}{ Time factor } & \multicolumn{3}{|c|}{ BLT-COPD group $(n=43)$} & \multicolumn{3}{|c|}{ SLT-COPD group $(n=58)$} \\
\hline & Coefficient & $95 \% \mathrm{Cl}$ & $P$ value & Coefficient & $95 \% \mathrm{Cl}$ & $P$ value \\
\hline \multicolumn{7}{|l|}{ Intubation time } \\
\hline PGD $0 \mathrm{~h}$ & 0.42 & 0.14 to 0.65 & $<.01$ & 0.40 & 0.09 to 0.64 & $<.05$ \\
\hline PGD $24 \mathrm{~h}$ & 0.42 & 0.13 to 0.64 & $<.01$ & 0.31 & -0.01 to 0.58 & .05 \\
\hline PGD $48 \mathrm{~h}$ & 0.50 & 0.21 to 0.70 & $<.001$ & 0.19 & -0.14 to 0.48 & .27 \\
\hline $\begin{array}{l}\text { PGD } 72 \text { h } \\
\text { ICU stay }\end{array}$ & 0.45 & 0.17 to 0.67 & $<.01$ & 0.39 & 0.06 to 0.65 & $<.05$ \\
\hline PGD $0 \mathrm{~h}$ & 0.49 & 0.21 to 0.69 & $<.001$ & 0.35 & 0.08 to 0.57 & $<.05$ \\
\hline PGD $24 \mathrm{~h}$ & 0.35 & 0.15 to 0.59 & $<.05$ & 0.28 & 0.01 to 0.51 & $<.05$ \\
\hline PGD $48 \mathrm{~h}$ & 0.59 & 0.34 to 0.76 & $<.0001$ & 0.24 & -0.05 to 0.49 & .10 \\
\hline PGD $72 \mathrm{~h}$ & 0.56 & 0.31 to 0.74 & $<.0001$ & 0.38 & 0.09 to 0.61 & $<.05$ \\
\hline
\end{tabular}

$B L T$, Bilateral lung transplantation; $C O P D$, chronic obstructive pulmonary disease; $S L T$, single lung transplantation; $C l$, confidence interval; $P G D$, primary graft dysfunction. 


\section{COPD}

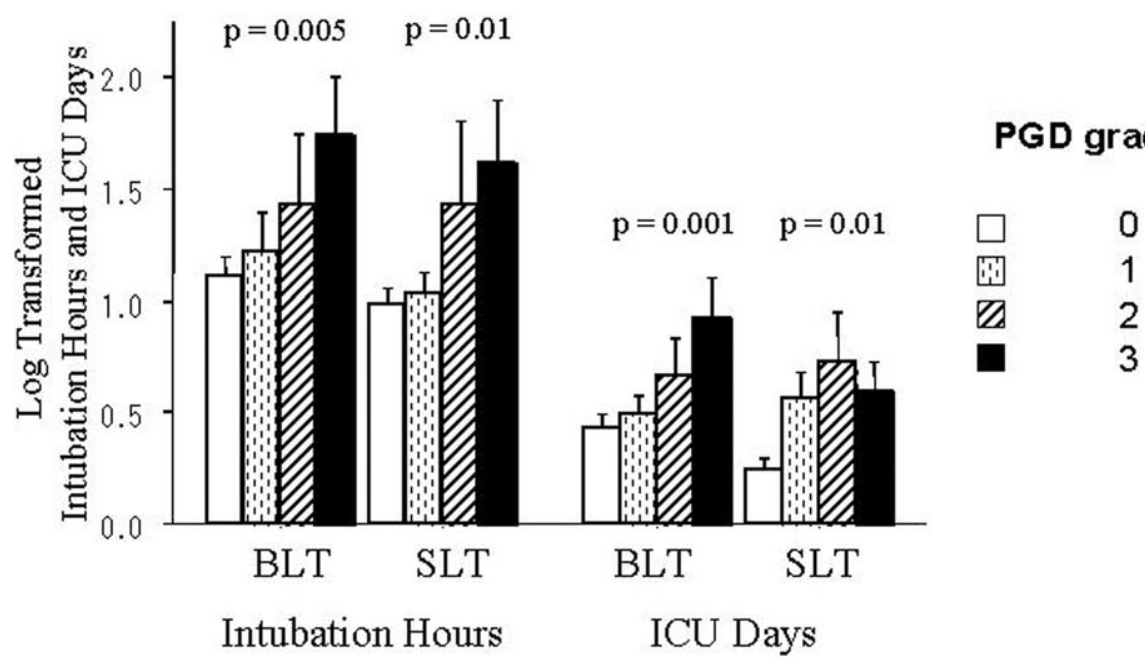

Figure 4. Duration of intubation and length of intensive care unit (ICU) stay stratified by primary graft dysfunction (PGD) grades at 0 hours (TO) in recipients with chronic obstructive pulmonary disease (COPD). Patients with a higher grade had longer duration of intubation and ICU stay in both bilateral lung transplantation (BLT) and single lung transplantation (SLT).

was seen at 0 and 72 hours; however, the correlations at 24 and 48 hours tended to be weak, and most of these did not reach statistical significance. Patients with a higher PGD grade at 0 hours had longer durations of intubation and ICU stay in the COPD subgroups (Figure 4).

\section{Oxygenation Before and After Extubation}

$\mathrm{PaO}_{2} / \mathrm{FIO}_{2}$ ratios before and after extubation are shown in Figure E2. In both the BLT-COPD and SLT-COPD subgroups, the $\mathrm{PaO}_{2} / \mathrm{FIO}_{2}$ ratio significantly decreased after extubation $(P<.0001)$; however, it recovered 12 hours after extubation, and there was no significant overall difference between the 2 subgroups $(P=.19)$.

\section{Thirty-day Mortality}

Eleven (4.8\%) of a total of 228 patients died within 30 days after transplantation; 7 of 11 were in the BLT-total group, and 4 of 11 were in the SLT-total group. PGD grades at 0 hours for the 7 patients in the BLT-total group were as follows: PGD grade $0(\mathrm{n}=2)$, PGD grade $1(\mathrm{n}=1)$, and PGD grade $3(n=4)$. All of the 4 deaths in the SLT-total group were PGD grade 3 at 0 hours. Although overall PGD grade was significantly associated with 30-day mortality (odds ratio, 1.81 [95\% CI, 1.04-3.14], $P=.03$ ), the cause of these deaths were cyclosporin neurotoxicity $(\mathrm{n}=3)$, nonspecific graft failure $(\mathrm{n}=2)$, Aspergillus species infection $(\mathrm{n}=2)$, and pulmonary embolism, liver failure, and multisystem organ failure $(\mathrm{n}=1$ each). Only 1 patient died directly of PGD.

\section{Discussion}

A standardized definition and grading system are necessary to determine the incidence, associations, and root causes of PGD. The ISHLT Working Group on Primary Graft Dysfunction has recently reported a standardized consensus defining criteria of PGD on the basis of $\mathrm{PaO}_{2} / \mathrm{FIO}_{2}$ ratios that they suggested should be applied to both BLT and SLT. ${ }^{8}$ However, this study describes quite different PGD grading for BLT and SLT, which is still evident when a single disease (ie, COPD) is analyzed. Although we detect a systematic PGD grading difference between BLT and SLT, it is of note that in reality the subsequent outcomes of ICU days and survival are the same across the 2 groups.

Time Issue for the First PGD Grading (T0)

According to the reported, standardized PGD-defining criteria, the blood gas measurement for the first PGD grading (T0) should be performed within 6 hours of final lung reperfusion, ideally measurement on an $\mathrm{FiO}_{2}$ of 1.0 and a positive endexpiratory pressure (PEEP) of $5 \mathrm{cmH}_{2} \mathrm{O}$ on mechanical ventilation. ${ }^{8}$ In this study all patients except one were admitted to the ICU within 6 hours after final reperfusion, and the time from final reperfusion to admission to the ICU was similar between the BLT-total and SLT-total groups. Therefore the first blood gas measurement in the ICU seemed to be ideal for the first PGD grading (T0), as described in the ISHLT report, because ventilator settings and measurements can be standardized. ${ }^{8}$ However, it should be noted that $20 \%$ of patients in the 
SLT-total group were already extubated at the time of admission to the ICU.

\section{Differences in $\mathrm{PaO}_{2} / \mathrm{FrO}_{2}$ Ratios Between the BLT and SLT Groups}

Previous literature described that inferior lung function, including lower oxygenation, is seen in SLT recipients when compared with BLT recipients 3 months after transplantation. ${ }^{23}$ In the current study the $\mathrm{PaO}_{2} / \mathrm{FIO}_{2}$ ratio in the SLT group was significantly lower than that in the BLT group throughout the first 72 hours after transplantation (Figure 1). This lower $\mathrm{PaO}_{2} / \mathrm{FIO}_{2}$ ratio in the SLT group might be due to the effect of the contralateral native lung. In the SLT-COPD subgroup not only was there ventilationperfusion mismatch in the native lung, but there was also a lower PEEP during mechanical ventilation to avoid native lung hyperinflation. Both of these factors might contribute to a lower $\mathrm{PaO}_{2} / \mathrm{FIO}_{2}$ ratio after transplantation. However, against this conclusion, a significantly lower $\mathrm{PaO}_{2} / \mathrm{FIO}_{2}$ ratio in SLT recipients was also seen in patients with ILD in this study (data not shown). In ILD the pattern of ventilationperfusion maldistribution is quite different from that seen in COPD. Also in patients with ILD, similar PEEP settings are applied to both BLT and SLT. Therefore being disease independent, the lower $\mathrm{PaO}_{2} / \mathrm{FIO}_{2}$ ratio in SLT recipients seems to be a relatively constant variable because of ventilation-perfusion mismatch of the native lung, regardless of the exact pattern of the mismatch.

Although the $\mathrm{PaO}_{2} / \mathrm{FIO}_{2}$ ratio was significantly lower in the SLT recipients than in the BLT recipients, the duration of intubation was shorter in the SLT-total group $(P=.03)$ and tended to be shorter in the SLT-COPD subgroup $(P=$ .14) than that in the BLT-total and BLT-COPD groups, respectively. These paradoxical outcomes raised the possibility of a possible artifact related to extubation. Extubation might have resulted in the loss of PEEP, with the $\mathrm{PaO}_{2} / \mathrm{FIO}_{2}$ ratio significantly decreasing after extubation $(P<.0001)$. Although the effect of extubation on the $\mathrm{PaO}_{2} / \mathrm{FIO}_{2}$ ratio between the 2 COPD subgroups was not significantly different (Figure E2), the higher incidence of extubation in the SLT group might result in a lower $\mathrm{PaO}_{2} / \mathrm{FIO}_{2}$ ratio and a higher PGD grade compared with those seen in the BLT group at the same time point.

\section{Differences in PGD Between the BLT and SLT Groups}

Reported incidences of PGD have varied from $11 \%$ to $25 \%$ over transplant centers because each center used a different definition of PGD and different time points after transplantation. ${ }^{1,6,24,25}$ Minimal actual clinical information regarding the incidence of PGD as defined by the ISHLT consensus grading system is available. From the very recent literature, Prekker and associates ${ }^{26}$ reported in an abstract that the incidence of severe PGD grade 3 was 25\% at 0 hours, 5.4\% at 24 hours, and $14 \%$ at 48 hours. However, the type of transplantation is not used as a defining criteria. This is indeed similar to the overall incidence of grade 3 PGD in the current study (32\% at 0 hours, $17 \%$ at 24 hours, $15 \%$ at 48 hours, and $12 \%$ at 72 hours).

Most previous PGD studies have not identified the type of transplantation as a risk factor of PGD. ${ }^{1,2,6,25}$ The available literature is confusing. Some studies have described a higher incidence of PGD in BLT, ${ }^{4,13}$ and in contrast, another study has described a higher incidence of PGD in SLT among patients with COPD. ${ }^{14}$ Many factors, including background, different prevalence of a PGD diagnosis, and cardiopulmonary bypass use, have potentially confounded the results. ${ }^{4,13}$

In the current study the higher incidence of PGD defined by the ISHLT consensus grading system was seen in the SLT group, and this was also seen separately among the subgroups of patients with COPD and ILD (data not shown), and yet early outcomes in SLT tended to be better than that in the BLT group, especially duration of intubation. These seemingly contradictory results might be explained by the effects of the native lung and possible artifact related to extubation in patients undergoing SLT. PGD grades at multiple time points in this study were well correlated with the early outcomes; however, the correlation in the BLT group tended to be stronger than that in the SLT group at 24 and 48 hours. In SLT recipients the native lung potentially contributed to lower $\mathrm{PaO}_{2} / \mathrm{FIO}_{2}$ ratios and a consequently higher PGD grade, regardless of the performance of the transplanted graft. This effect might decrease the accuracy of the PGD grading as a predictor of the early outcomes for SLT. Therefore we suggest that PGD grades in BLT and SLT should be considered and used separately.

In the analysis of 30-day mortality, although overall PGD grade was significantly associated with 30-day mortality, we could not detect any difference between BLT and SLT because of the small number of events. A further study including a larger number of patients is necessary to investigate the potential different effects of PGD on BLT and SLT 30-day mortality.

\section{Conclusion}

The prevalence of PGD grade between BLT and SLT is different. The incidence of grade 3 PGD varies over time in both transplantation types, always tending to be more common in SLT. The current definition of PGD in BLT and SLT appears to have clinical utility in both transplantation types because the PGD grade correlated with the early posttransplantation outcomes in both BLT and SLT. However, for the purposes of description and further studies, the incidence of the various PGD grades in BLT and SLT should be considered separately. 
We thank Sharon Daly for assembling and verifying the clinical data, and we also wish to extend our appreciation to members of the Heart and Lung Transplant Service, The Alfred Hospital for their assistance, and the Margaret Pratt Foundation and the Alfred Foundation for their financial support.

\section{References}

1. Christie JD, Kotloff RM, Pochettino A, Arcasoy SM, Rosengard BR, Landis JR, et al. Clinical risk factors for primary graft failure following lung transplantation. Chest. 2003;124:1232-41.

2. Thabut G, Vinatier I, Stern JB, Lesèche G, Loirat P, Fournier M, et al. Primary graft failure following lung transplantation: predictive factors of mortality. Chest. 2002;121:1876-82.

3. Oto T, Levvey B, Pilcher DV, Bailey MJ, Snell GI. Evaluation of the oxygenation ratio in the definition of early graft dysfunction post lung transplantation. J Thorac Cardiovasc Surg. 2005;130:180-6.

4. Chatila WM, Furukawa S, Gaughan JP, Criner GJ. Respiratory failure after lung transplantation. Chest. 2003;123:165-73.

5. Lee KH, Martich GD, Boujoukos AJ, Keenan RJ, Griffith BP. Predicting ICU length of stay following single lung transplantation. Chest. 1996;110:1014-7.

6. Khan SU, Salloum J, O'Donovan PB, Mascha EJ, Mehta AC, Matthay MA, et al. Acute pulmonary edema after lung transplantation: the pulmonary reimplantation response. Chest. 1999;116:187-94.

7. Christie JD, Van Raemdonck D, de Perrot M, Barr M, Keshavjee S, Arcasoy S, et al. Report of the ISHLT working group on primary lung graft dysfunction part I: introduction and methods. J Heart Lung Transplant. 2005;24:1451-3.

8. Christie JD, Carby M, Bag R, Corris P, Hertz M, Well D. Report of the ISHLT working group on primary lung graft dysfunction part II: Definition. A consensus statement of the International Society for Heart and Lung Transplantation. J Heart Lung Transplant. 2005;24: 1454-9.

9. de Perrot M, Bonser RS, Dark J, Kelly RF, McGiffin D, Menza R, et al. Report of the ISHLT working group on primary lung graft dysfunction part III: Donor-related risk factors and markers. J Heart Lung Transplant. 2005;24:1460-7.

10. Barr MI, Kawut SM, Whelan TP, Girgis R, Böttcher H, Sonett J, et al. Report of the ISHLT working group on primary lung graft dysfunction part IV: Recipient-related risk factors and markers. J Heart Lung Transplant. 2005;24:1468-82.

11. Arcasoy SM, Fisher A, Hachem RR, Scavuzzo M, Ware LB. Report of the ISHLT working group on primary lung graft dysfunction part V: predictors and outcomes. J Heart Lung Transplant. 2005;24:1483-8.

12. Shargall Y, Guenther G, Ahya VN, Ardehali A, Singhal A, Keshavjee S. Report of the ISHLT working group on primary lung graft dysfunction part VI: treatment. J Heart Lung Transplant. 2005;24:1489-500.
13. Fiser SM, Kron IL, McLendon Long S, Kaza AK, Kern JA, Tribble CG. Early intervention after severe oxygenation index elevation improves survival following lung transplantation. J Heart Lung Transplant. 2001;20:631-6.

14. Bavaria JE, Kotloff R, Palevsky H, Rosengard B, Roberts JR, Wahl $\mathrm{PM}$, et al. Bilateral versus single lung transplantation for chronic obstructive pulmonary disease. J Thorac Cardiovasc Surg. 1997;113: 520-8.

15. de Perrot M, Snell GI, Babcock WD, Meyers BF, Patterson GA, Hodges TN, et al. Strategies to optimize the use of currently available lung donors. J Heart Lung Transplant. 2004;23:1127-34.

16. Gabbay E, Williams TJ, Griffiths AP, Macfarlane LM, Kotsimbos TC, Esmore DS, et al. Maximizing the utilization of donor organs offered for lung transplantation. Am J Respir Crit Care Med. 1999;160:26571.

17. Oto T, Griffiths AP, Levvey B, Pilcher DV, Whitford H, Kotsimbos TC, et al. A donor history of smoking affects early but not late outcome from lung transplantation. Transplantation. 2004;78:599606.

18. de Perrot, Keshavjee S. Lung preservation. Semin Thorac Cardiovasc Surg. 2005;16:300-8.

19. Oto T, Rabinov M, Griffiths AP, Whitford H, Levvey BJ, Esmore DS, et al. Unexpected donor pulmonary embolism affects early outcomes after lung transplantation: a major mechanism of primary graft failure? J Thorac Cardiovasc Surg. 2005;130:1446-52.

20. Oto T, Rabinov M, Rosenfeldt F, Esmore DS. Extended pericardiotomy avoids cardiopulmonary bypass during bilateral sequential lung transplantation. J Thorac Cardiovasc Surg. 2005;129:466-7.

21. Pilcher DV, Scheinkestel CD, Snell GI, Davey-Quinn A, Bailey MJ, Williams TJ. High central venous pressure is associated with prolonged mechanical ventilation and increased mortality after lung transplantation.J Thorac Cardiovasc Surg. 2005;129:912-8.

22. Oto T, Rosenfeldt F, Rowland M, Pick A, Rabinov M, Preovolos A, et al. Extracorporeal membrane oxygenation after lung transplantation: evolving technique improves outcomes. Ann Thorac Surg. 2004;78: 1230-5.

23. Williams TJ, Grossman RF, Maurer JR. Long-term functional follow-up of lung transplant recipients. Clin Chest Med. 1990;11:347-58.

24. Meyers BF, de la Morena M, Sweet SC, Trulock EP, Guthrie TJ, Mendeloff EN, et al. Primary graft dysfunction and other selected complications of lung transplantation: a single-center experience of 983 patients. J Thorac Cardiovasc Surg. 2005;129:1421-9.

25. King RC, Binns OA, Rodriguez F, Kanithanon RC, Daniel TM, Spotnitz WD, et al. Reperfusion injury significantly impacts clinical outcome after pulmonary transplantation. Ann Thorac Surg. 2000;69: 1681-5.

26. Prekker ME, Nath DS, Johnson AC, Walker AR, Hertz MI, Dahlberg PS, et al. Validation of the proposed ISHLT grading system for primary graft dysfunction following lung transplantation. J Heart Lung Transplant. 2005;24(suppl):S72. 
Table E1. Demographics of the donor and recipient

\begin{tabular}{|c|c|c|c|c|c|c|}
\hline & \multicolumn{3}{|c|}{ Total lung transplantations $(\mathrm{n}=\mathbf{2 2 8}$ ) } & \multicolumn{3}{|c|}{ COPD $(n=101)$} \\
\hline & BLT-total $(n=149)$ & SLT-total $(n=79)$ & $P$ value & BLT-COPD (n = 43) & SLT-COPD (n = 58) & $P$ value \\
\hline \multicolumn{7}{|l|}{ Donor } \\
\hline Age (y) & $36 \pm 1$ & $37 \pm 2$ & $>.1$ & $37 \pm 2$ & $39 \pm 2$ & $>.1$ \\
\hline $\operatorname{Sex}(M / F)$ & $86 / 63$ & $56 / 23$ & .06 & $33 / 10$ & $38 / 20$ & $>.1$ \\
\hline Cause of death & & & $>.1$ & & & $>.1$ \\
\hline CVA & 71 & 31 & & 19 & 24 & \\
\hline Trauma & 49 & 31 & & 15 & 21 & \\
\hline Anoxia & 20 & 8 & & 6 & 7 & \\
\hline Others & 9 & 9 & & 3 & 6 & \\
\hline $\mathrm{PaO}_{2} / \mathrm{FlO}_{2}$ ratio & $465 \pm 8$ & $474 \pm 10$ & $>.1$ & $463 \pm 13$ & $479 \pm 12$ & $>.1$ \\
\hline \multicolumn{7}{|l|}{ Recipient } \\
\hline Age (y) & $40 \pm 1$ & $57 \pm 1$ & $<.0001$ & $52 \pm 1$ & $57 \pm 1$ & $<.001$ \\
\hline $\operatorname{Sex}(M / F)$ & $88 / 61$ & $48 / 31$ & $>.1$ & $29 / 14$ & $29 / 29$ & $>.1$ \\
\hline Diagnosis & & & $<.0001$ & & & \\
\hline COPD & 43 & 58 & & 43 & 58 & \\
\hline $\mathrm{CF}$ & 76 & 0 & & & & \\
\hline ILD & 17 & 21 & & & & \\
\hline $\mathrm{PH}$ & 13 & 0 & & & & \\
\hline CPB use & 31 & 10 & $>.1$ & 1 & 2 & $>.1$ \\
\hline Ischemic time (min) & $401 \pm 11$ & $369 \pm 17$ & $>.1$ & $383 \pm 21$ & $368 \pm 20$ & $>.1$ \\
\hline
\end{tabular}

COPD, Chronic obstructive pulmonary disease; $B L T$, bilateral lung transplantation, $S L T$, single lung transplantation; CVA, cerebrovascular accident; $\mathrm{PaO}_{2} / \mathrm{FIO}_{2}$, ratio of arterial oxygen tension to inspired oxygen consumption; $C F$, cystic fibrosis; ILD, interstitial lung disease; $P H$, pulmonary hypertension, $C P B$, cardiopulmonary bypass.

\section{COPD}
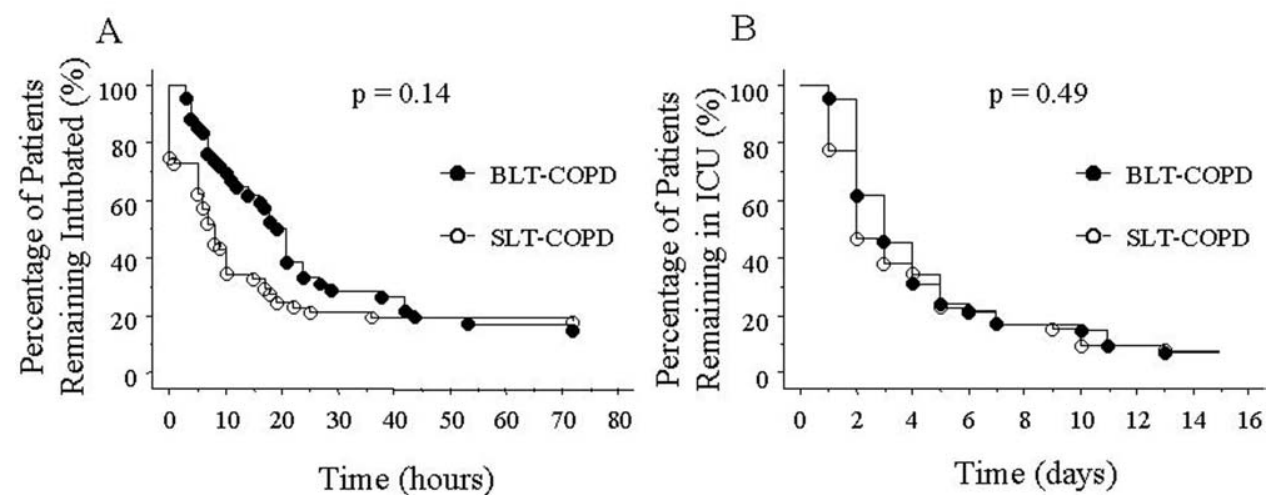

Figure E1. A, Percentage of patients remaining to be intubated. B, Percentage of patients remaining in the intensive care unit (ICU). BLT, Bilateral lung transplantation; COPD, chronic obstructive pulmonary disease; $S L T$, single lung transplantation. 


\section{COPD}

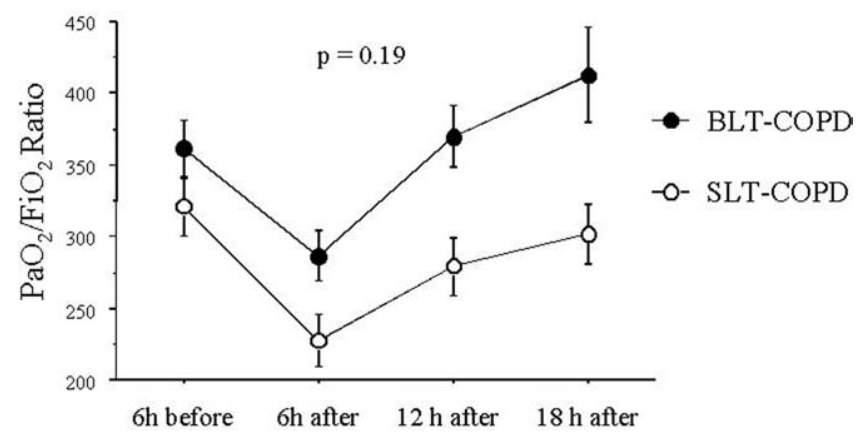

Time Before and After Extubation (hours)

Figure E2. $\mathrm{PaO}_{2} /$ fraction of inspired oxygen $\left(\mathrm{FlO}_{2}\right)$ ratio before and after extubation in recipients with chronic obstructive pulmonary disease (COPD). BLT, Bilateral lung transplantation; SLT, single lung transplantation. 